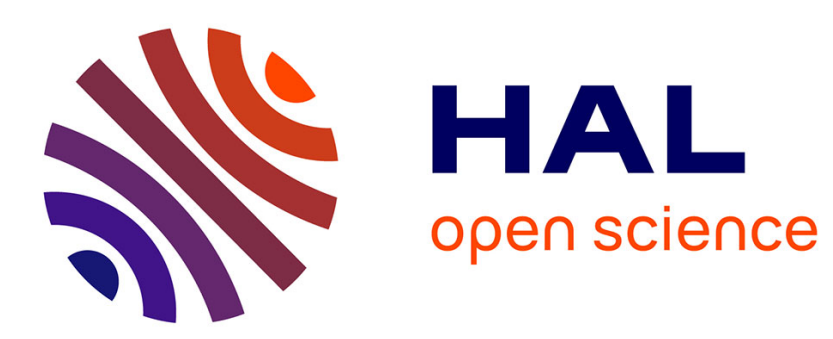

\title{
Controllable Production Rate and Quality Improvement in a Two-Echelon Supply Chain Model
}

Mitali Sarkar, Byung Do Chung

\section{To cite this version:}

Mitali Sarkar, Byung Do Chung. Controllable Production Rate and Quality Improvement in a TwoEchelon Supply Chain Model. IFIP International Conference on Advances in Production Management Systems (APMS), Aug 2018, Seoul, South Korea. pp.238-245, 10.1007/978-3-319-99704-9_29 . hal02164844

\section{HAL Id: hal-02164844 \\ https://hal.inria.fr/hal-02164844}

Submitted on 25 Jun 2019

HAL is a multi-disciplinary open access archive for the deposit and dissemination of scientific research documents, whether they are published or not. The documents may come from teaching and research institutions in France or abroad, or from public or private research centers.
L'archive ouverte pluridisciplinaire HAL, est destinée au dépôt et à la diffusion de documents scientifiques de niveau recherche, publiés ou non, émanant des établissements d'enseignement et de recherche français ou étrangers, des laboratoires publics ou privés. 


\title{
Controllable production rate and quality improvement in a two-echelon supply chain model
}

\author{
MITALI SARKAR ${ }^{1[0000-0002-4549-3035]}$ and BYUNG Do CHUNG 2[0000-0003-1878-1338] \\ ${ }^{1}$ Department of Industrial \& Management Engineering, Hanyang University, Ansan, \\ Gyeonggi-do, 15588, South Korea. \\ 2 Department of Industrial Engineering, Yonsei University, 50 Yonsei-ro, Seodaemun-gu, \\ Seoul, South Korea. \\ bd.chung@yonsei.ac.kr
}

\begin{abstract}
The flexible production plays the key role within any production system. An optimization model is developed for a production system with flexible production rate within a fixed limit, defined by the management, with quality improvement in a supply chain management. The aim of the model is to obtain the best optimum production rate with the global minimum cost. It is assumed that the lead time demand follows a normal distribution and a lead time crashing cost is used to reduce the lead time. A classical optimization technique is used to solve the supply chain model. A theorem is established to obtain the global minimum total cost. A numerical example is given to illustrate the model. Numerical studies prove that this model converges over the existing literature at the global minimum cost.
\end{abstract}

Keywords: Flexible Production Rate, Supply Chain Management, Quality Improvement, Controllable Lead Time.

\section{Introduction}

Supply chain management (SCM) is introduced by Goyal [1], where he thought about the basic combination of buyer and vendor. There was no especial policy except the adding the basic cost of two players. After a decade, another researcher Banerjee [2] incorporated a new strategy lot-for-lot (LFL) within SCM model, where it is found that LFL policy is convergent over basic model of Goyal [1]. Just after 2 years of Banerjee's [2] model, Goyal [3] wrote a short note over a major concept as single-setup-multidelivery (SSMD) policy. The policy is valid when the buyer's holding cost is less than vender's holding cost. But there is a trade-off between holding cost and transportation cost of buyer. Sarkar et al. [4] extended SSMD policy to single-setup-multi-unequaldelivery (SSMUD) policy, where they proved that SSMUD is always convergent over SSMD policy. Even though SSMUD is the best strategy for transportation policy till now, but the trade-off between two different costs exist till now. The whole invention is within the grip of domestic deterministic modelling, where the basic aim of proposed model is to consider a probabilistic modelling with some real extensions. 
The basic inventory model for SCM with continuous controllable lead time is considered by Ben-Daya and Rauf [5]. The controllable lead time crashing cost with discrete lead time crashing is initially utilized by Ouyang et al. [6], whereas that model is modified by Moon and Choi [7]. The concepts of quality improvement and setup cost reduction were introduced by Ouyang et al. [8]. This model of Ouyang et al. [8] was extended by Sarkar and Moon [9] by controllable lead time dependent backorder rate but with continuous investment for setup cost reduction. Sarkar et al. [4] extended the concept of quality improvement with backorder price discounts. Kim and Sarkar [10] extended the same field with multi-stage production system Majumder et al. [11] developed a SCM model with similar direction for quality improvement. There are several extensions in this direction, but no one considered variable production rate with SSMUD policy in supply chain management (SCM). Nowadays, it is found that constant production rate (Glock, [12]) may not support always for different types of rapid production. Glock [13] proved that production rate may be variable or controllable but not constant for all production systems. The production rate should be controllable as if machine moves to out-of-control state, it may produce defective products. Thus, to control defective products or imperfect quality items, production rate should be reduced or due to urgent production, production rate may increase to a certain limit for rapid production. Therefore, production rate is always constant, it is not always valid for all production system. The proposed model considers a SCM model with SSMUD policy under variable production rate, which is the initial stage to make a sustainable supply chain management through sustainable manufacturing which follows a normal distribution. The total cost is minimized through a classical optimization technique.

The rest of the paper is organized as follows: Section 2 explains mathematical model of the research problem. Section 3 contains the numerical results of the model. Finally, conclusions and future extensions are discussed in Section 4.

\section{$2 \quad$ Mathematical model}

A basic two-echelon supply chain management is considered for single type of products within single-manufacturer and single-buyer. The Production rate $P$ is variable and it is considered as $f(P)=a P+\frac{b}{p} ; a$ and $b$ are scaling parameters and $P$ is the production rate with production setup cost $S$ per setup. The unit production cost is production dependent (see for reference Sarkar et al. [14]) and the quality improvement with continuous investment is considered here (see for reference Kim and Sarkar [10]). If the buyer orders $Q$ items, manufacturer produces $z Q$ items and transports them into $z$ times of shipments to buyer. The reorder point $\mathrm{R}$ of each buyer is allowed when the inventory touches the reorder point $R=D L+k \sigma \sqrt{L}$, where $D$ is the demand of products during unit time, $L$ is average lead time, $D L$ is the expected demand during lead time, $k \sigma \sqrt{L}$ is safety stock, and $k$ is safety factor. Safety factor is considered as a decision variable instead of reorder point. Let us suppose $L_{0} \equiv \sum_{j=1}^{n} v_{j}$ and $L_{i}$ be the length of lead time with components $1,2, \ldots ., i$ crashed to their minimum duration. Thus, $L_{i}$ can be expressed as $L_{i} \equiv \sum_{j=1}^{i}\left(v_{j}-u_{j}\right), i=1,2 \ldots ., n$; where $u_{j}$ and $v_{j}$ are the minimum duration and normal duration to crash the lead time. The lead time crashing cost per cycle $C(L)$ is expressed as $C(L)=c_{i}\left(L_{i-1}-L\right)+\sum_{j=1}^{i-1} c_{j}\left(v_{j}-u_{j}\right), L \in\left[L_{i}, L_{i-1}\right]$, where $c_{i}$ 
is the crashing cost per unit time. Due to controllable lead time shortages are allowed and fully backlogged.

The average total cost of manufacturer is

$$
\begin{aligned}
\mathrm{TC}_{\mathrm{M}}(\mathrm{z}, \mathrm{Q}, \mathrm{P}, \gamma) & =\frac{\mathrm{SD}}{\mathrm{zQ}}+\mathrm{h}_{\mathrm{m}} \frac{\mathrm{zQ}}{2}\left[\mathrm{z}\left(1-\frac{\mathrm{D}}{\mathrm{f}(\mathrm{P})}\right)-1+\frac{2 \mathrm{D}}{\mathrm{f}(\mathrm{P})}\right]+\frac{\mathrm{yDzQ} \gamma}{2} \\
+ & \left(\mathrm{C}_{\mathrm{m}}+\frac{\mathrm{C}_{\mathrm{d}}}{\mathrm{f}(\mathrm{P})}+\alpha \mathrm{f}(\mathrm{P})\right) \mathrm{D}+\mathrm{B} \ln \left(\frac{\gamma_{0}}{\gamma}\right) \\
+ & \frac{\mathrm{F}_{1} \mathrm{D}}{\mathrm{Q}} .
\end{aligned}
$$

For the manufacturer, the average total cost is combination of setup cost, holding cost, investment for imperfect products, variable production cost, quality improvement cost, and transportation cost, respectively. Here $h_{m}$ is the holding cost of the manufacturer per unit product per unit time, $y$ is the investment for quality improvement, $C_{m}$ and $C_{d}$ are material cost and development cost, $\alpha$ is the tool/dye cost, $\gamma$ is the probability for shifting "in-control" state to "out-of-control" state of the manufacturing process, $\gamma_{0}$ is the initial probability to go "out-of-control" state, B is the scaling parameter related with the quality of product, and $F_{1}$ is the transportation cost of the manufacturer.

The average total cost of buyer is

$T C_{B}(Q, k, L)=\left[\frac{A D}{Q}+\frac{D C(L)}{Q}+h_{b}\left[\frac{Q}{2}+R-D L\right]+\frac{\pi D}{Q} E(X-R)^{+}\right]$,

which is the summation of ordering cost, lead time crashing cost, holding cost, and shortage cost. Here $A$ is the ordering cost per order and $h_{b}$ is the holding cost of the buyer per unit per unit time, and $\pi$ is shortage cost per unit shortage.

The expected shortage at the end of the cycle can be written as

$$
\begin{gathered}
E(X-R)^{+}=\int_{R}^{\infty}(x-R) d F(x) \\
=\sigma \sqrt{L} \psi(K)
\end{gathered}
$$

, where $\psi(k)=\phi(k)-k[1-\Phi(k)]$, $\phi$ stands for the standard normal probability density function and $\Phi$ stands for the cumulative distribution function of normal distribution.

Total supply chain cost can be found as the summation of total cost of two players. Therefore,

$$
\begin{gathered}
T C_{S}(z, Q, P, \gamma, k, L)=\frac{\mathrm{SD}}{\mathrm{zQ}}+\mathrm{h}_{\mathrm{m}} \frac{\mathrm{zQ}}{2}\left[\mathrm{z}\left(1-\frac{\mathrm{D}}{\mathrm{f}(\mathrm{P})}\right)-1+\frac{2 \mathrm{D}}{\mathrm{f}(\mathrm{P})}\right]+\frac{\mathrm{yDzQ} \gamma}{2}+ \\
\left(\mathrm{C}_{\mathrm{m}}+\frac{\mathrm{C}_{\mathrm{d}}}{\mathrm{f}(\mathrm{P})}+\alpha \mathrm{f}(\mathrm{P})\right) \mathrm{D}+\mathrm{B} \ln \left(\frac{\gamma_{0}}{\gamma}\right)+\frac{\mathrm{F}_{1} \mathrm{D}}{\mathrm{Q}}+\left[\frac{A D}{Q}+\frac{D C(L)}{Q}+h_{b}\left[\frac{Q}{2}+R-D L\right]+\right. \\
\left.\frac{\pi D}{Q} E(X-R)^{+}\right]
\end{gathered}
$$

Taking partial differentiation with respect to $Q$, and after simplification, one can be obtained

$$
Q=\sqrt{\frac{A D+F_{1} D+D C(L)+\pi D \sigma \sqrt{L} \psi(K)+\frac{S D}{z}}{\frac{h_{m z}}{2}\left[z\left(1-\frac{D}{f(P)}\right)-1+\frac{2 D}{f(P)}\right]+\frac{y D z \gamma}{2}+\frac{h_{b}}{2}}}
$$


Partially differentiating equation (4), with respect to $P$ and after simplifying, one can find

$$
P=\frac{\sqrt{\frac{1}{\alpha}\left[C_{d}-\frac{h_{m} z Q(z-2)}{2}\right]}+\sqrt{\frac{1}{\alpha}\left[C_{d}-\frac{h_{m} z Q(z-2)}{2}\right]-4 a b}}{2 a}
$$

For obtaining the optimum value of $k$, one can take the partial differentiation of the total supply chain cost with respect to $k$ and after simplification, one can have

Solving the equation, it can be found

$$
h_{b} \sigma \sqrt{L}+\frac{\pi D \sigma \sqrt{L}}{Q}(\Phi(k)-1)=0 .
$$

$$
\Phi(k)=1-\frac{h_{b} Q}{D \pi} .
$$

Differentiating partially twice with respect to $L$ of the total cost function, it can be obtained

$$
\frac{\partial^{2} T C_{S}}{\partial L^{2}}=-\frac{1}{4}\left[\frac{h_{b} k \sigma}{L^{3 / 2}}+\frac{\pi D \sigma \psi(K)}{Q L^{3 / 2}}\right]
$$

The total cost function $T C_{S}$ is concave with respect to $L$ as second order derivative with respect to $L$ is less than zero. For optimum value of $\gamma$, differentiating the total cost function and simplifying, one can obtain,

$$
\gamma=\frac{2 B}{Y D z Q} \text {. }
$$

These values of the decision variables are optimum values as the principal minors are positive definite always.

\section{$3 \quad$ Numerical experiment}

This section consists of experiment's result and analysis from the results.

\subsection{Numerical example}

To test the model, an illustrative numerical experiment is conducted. The experiment is considered with a tool as MATLAB 17B. For the experiment, the input parameters' value are taken from Majumder et al. [11] and given below:

The demand of products is considered here 600 unit/cycle. The ordering cost of the retailer is $\$ 200$ /order. Shortages are allowed in this model and it is considered as $\$ 10 /$ unit shortage. Safety $\sigma$ has the fixed value of 7 . Setup cost is assumed as \$200/setup. $\gamma_{0}$ is the initial probability to shift "out-of-control" state 0.0002; $F_{1}=\$ .1 /$ shipment; The investment for quality improvement is $\$ 175$. The holding cost of the manufacturer is considered as $\$ 0.13 /$ unit/unit time and buyer as $\$ 0.18$ /unit/unit time. Material cost, development cost and tool/dye cost are assumed as \$3/setup, \$10/setup, and $\$ 0.001 /$ cycle, respectively. Scaling parameters' values are $a=0.05$ and $b=500$, and $B=400$. Lead time crashing cost is $\$ 22.4$.

The numerical experiment has been done with the given values of the parameters. The model obtains the global optimal solution using classical optimization technique in MATLAB coding. The optimum values of equations (5) (10) are used to obtain the optimum results. The optimal results are obtained as follows: the optimum supply chain cost $T C_{S}=\$ 5929.88$; the optimal lot size $\left(Q^{*}\right)=28.26$ unit; the optimal probability of 
shifting to "out-of-control" state from "in-control" state $\gamma^{*}=0.00009$; the optimal production rate $\left(P^{*}\right)=3.33$ units; $k^{*}=1.37$ the number of shipments $(z)=3$; lead time $(L)=4$. It is found that optimum production rate is more than the demand, which indicates that there should not be any shortages any time and the model is validated with the theoretical perspective based on the taken assumptions. Based on the probability value of shifting to "out-of-control" state from "in-control" state, it can be concluded that the quality of products is improved as the probability is reduced, and finally the shipment number indicates that the model follows single-setup-multi-delivery policy.

If we compare this research model with Majumder et al. [11], then the cost of their model is \$ 6393.17 under same assumptions whereas the proposed model gives the cost $\$ 5929.88$. Therefore, the savings from the existing literature is $7.18 \%$.

\subsection{Sensitivity analysis}

A sensitivity analysis is performed here to estimate the variation of total cost of supply chain with change of key parameters of the model. The optimal value of total cost is changed $(-10 \%,-5 \%,+5 \%,+10 \%)$ with the change of different parameters are given below in Table 1.

Table 1 . Sensitivity analysis table

\begin{tabular}{|c|c|c|c|c|c|}
\hline $\begin{array}{l}\text { Param- } \\
\text { eters }\end{array}$ & $\begin{array}{c}\text { Changes } \\
\text { (in \%) }\end{array}$ & $\begin{array}{c}T C_{s}^{*} \\
\text { (in \%) }\end{array}$ & $\begin{array}{l}\text { Param- } \\
\text { eters }\end{array}$ & $\begin{array}{c}\text { Changes } \\
\text { (in \%) }\end{array}$ & $\begin{array}{r}T C_{s}^{*} \\
\text { (in \%) }\end{array}$ \\
\hline \multirow[t]{4}{*}{ A } & -10 & -0.05 & \multirow[t]{4}{*}{$\pi$} & -10 & -0.004 \\
\hline & -5 & -0.03 & & -5 & -0.001 \\
\hline & +5 & +0.02 & & +5 & -0.0001 \\
\hline & +10 & +0.05 & & +10 & $+0: 001$ \\
\hline \multirow[t]{4}{*}{$S$} & -10 & -0.02 & \multirow[t]{4}{*}{$\sigma$} & -10 & +0.03 \\
\hline & -5 & -0.01 & & -5 & +0.01 \\
\hline & +5 & +0.01 & & +5 & -0.01 \\
\hline & +10 & +0.02 & & +10 & -0.03 \\
\hline \multirow{4}{*}{$\gamma_{0}$} & -10 & -0.007 & \multirow[t]{4}{*}{$F_{1}$} & -10 & -0.00003 \\
\hline & -5 & -0.003 & & -5 & -0.00001 \\
\hline & +5 & +0.003 & & +5 & +0.00001 \\
\hline & +10 & +0.006 & & +10 & +0.00003 \\
\hline \multirow[t]{4}{*}{$\mathrm{Y}$} & -10 & -0.007 & \multirow[t]{4}{*}{$\alpha$} & -10 & -0.002 \\
\hline & -5 & -0.003 & & -5 & -0.001 \\
\hline & +5 & +0.003 & & +5 & +0.001 \\
\hline & +10 & +0.006 & & +10 & +0.002 \\
\hline \multirow[t]{4}{*}{$h_{m}$} & -10 & -0.01 & \multirow[t]{4}{*}{$h_{b}$} & -10 & -0.03 \\
\hline & -5 & -0.006 & & -5 & -0.01 \\
\hline & +5 & +0.005 & & +5 & +0.01 \\
\hline & +10 & +0.01 & & +10 & +0.03 \\
\hline$C_{m}$ & -10 & -0.03 & & -10 & +0.001 \\
\hline
\end{tabular}




\begin{tabular}{|c|c|c|c|c|c|}
\hline & -5 & -0.02 & \multirow{3}{*}{$C_{d}$} & -5 & +0.0005 \\
\hline & +5 & +0.02 & & +5 & -0.0003 \\
\hline & +10 & +0.03 & & +10 & -0.0005 \\
\hline \multirow[t]{4}{*}{$a$} & -10 & +0.002 & \multirow[t]{4}{*}{ b } & -10 & -0.002 \\
\hline & -5 & +0.0008 & & -5 & -0.0008 \\
\hline & +5 & -0.0007 & & +5 & +0.0008 \\
\hline & +10 & -0.001 & & +10 & +0.002 \\
\hline \multirow[t]{4}{*}{ B } & -10 & -0.02 & & & \\
\hline & -5 & -0.008 & & & \\
\hline & +5 & +0.008 & & & \\
\hline & +10 & +0.01 & & & \\
\hline
\end{tabular}

From Table 1, one can say that ordering cost, setup cost, material cost, backlogging cost, and transportation cost are changing as they are directly proportional to the total cost of the supply chain. Scaling parameters $(a, b)$ of flexible production rate are inversely and directly proportional, respectively to the total cost. For the controllable production rate development cost is inversely proportional to total cost of the supply chain.

\section{Conclusions}

Two-echelon supply chain model was considered where single-setup-multiple-delivery was applied. Production rate was variable and controllable. Manufacturing system always maintained quality of products. Buyer faced some shortages, but it was fully backlogged. To continue the business supply chain players had to follow some strategies. The model had been solved analytically and numerically. Analytically quasi-closed form solutions were obtained and from numerical study optimal total cost were gained. This model can be easily applied in any production system, where the production system is flexible and producing single-type of products. The model can be used where the production system is passing through a long-run production system and there is a probability for the production system moves from "in-control" state to "out-of-control" state; the policy from this model can be employed to improve the quality of products. This model can be extended with the setup time and transportation time-dependent lead time demand, which may be considered as controllable. One can invest some investments to reduce the setup time or transportation time or both. It may be considered that second setup is dependent on first setup and hence the lead time is dependent only setup time, which may be controllable also.

\section{References}

1. Goyal, S.K.: An integrated inventory model for a single supplier-single customer problem. International Journal of Production Research 15(1), 107-111 (1976). 
2. Banerjee, A.: A joint economic-lot-size model for purchaser and vendor. Decision Sciences 17(3), 292-311 (1986).

3. Goyal, S.K.: A joint economic-lot-size model for purchaser and vendor: a comment. Decision Sciences 19(1), 236-241 (1988).

4. Sarkar, B., Saren, S., Sinha, D. Hur, S.: Effect of unequal lot sizes, variable setup cost, and carbon emission cost in a supply chain model. Mathematical Problems in Engineering 1-13 (2015).

5. Ben-Daya, M. Raouf, A.: Inventory models involving lead time as a decision variable. The Journal of Opertional Research Society 45(5), 579-582 (1994).

6. Ouyang, L.Y., Yeh, N.C., Wu, K.S.: Mixture inventory model with backorders and lost sales for variable lead time. The Journal of Operational Research Society 47(6), 829-832 (1996).

7. Moon, I., Choi, S.: Technical note: a note on lead time and distributional assumptions in continuous review inventory models. Computers \& Operations Research 25(11), 1007-1012 (1998).

8. Ouyang, L.Y., Chen, C.K., Chang, H.C.: Quality improvement, setup cost and lead-time reductions in lot size reorder point models with an imperfect production process. Computers \& Operations Research 29(12), 1701-1717 (2002).

9. Sarkar, B., Moon, I.: Improved quality, setup cost reduction, and variable backorder costs in an imperfect production process. International Journal of Production Economics 155, 204-213 (2014).

10. Kim, M., Sarkar, B.: Multi-stage cleaner production process with quality improvement and lead time dependent ordering cost. Journal Cleaner Production 144, 572-590 (2017).

11. Majumder, A., Guchhait, R., Sarkar, B.: Manufacturing quality improvement and setup cost reduction in an integrated vendor-buyer supply chain model. European Journal of Industrial Engineering 11(5), (2017).

12. Glock, C. H.: A comment: Integrated single vendor-single buyer model with stochastic demand and variable lead time. International Journal of Production Economics 122(2), 790-792 (2009).

13. Glock, C. H.: The joint economic lot size problem: A review. International Journal of Production Economics 135(2), 671-686 (2012).

14. Sarkar, B. Sana, S. S., Chaudhuri, K. S.: An imperfect production process for time varying demand with inflation and time value of money - An EMQ model. Expert Systems with Applications 38, 13543-13548 (2011). 